\title{
Responsiveness of standard spine outcome tools: do they measure up?
}

\author{
Carolyn E. Schwartz, ScD, ${ }^{1-3}$ Roland B. Stark, MEd, ${ }^{1}$ Phumeena Balasuberamaniam, HBSc, ${ }^{4}$ \\ Mopina Shrikumar, HBSc, ${ }^{4}$ Abeer Wasim, HBSc, ${ }^{4}$ and Joel A. Finkelstein, MD, MSc, FRCS(C) ${ }^{4,5}$
}

\begin{abstract}
1DeltaQuest Foundation, Inc., Concord; Departments of ${ }^{2}$ Medicine and ${ }^{3}$ Orthopaedic Surgery, Tufts University School of Medicine, Boston, Massachusetts; and Divisions of ${ }^{4}$ Orthopedic Surgery and ${ }^{5}$ Spine Surgery, Sunnybrook Health Sciences Centre, Toronto, Ontario, Canada
\end{abstract}

\begin{abstract}
OBJECTIVE Over the past 2 decades, spine outcome research has become more standardized in response to recommendations from Deyo and others. By using the same generic and condition-specific patient-reported outcome (PRO) measures across studies, results are more easily compared. Given the challenges of maintaining high-quality data in clinical research studies, it would be important to evaluate the contribution of each PRO to confirm that it merits the respondent burden. This study aimed to examine the spine PROs' association with clinically important change and relative responsiveness in explaining variance in patients' global assessment of change (GAC).
\end{abstract}

METHODS This prospective longitudinal cohort study included adults recruited from 4 active spine surgery practices at a Toronto-based hospital. Patients were diagnosed with a degenerative lumbar spinal condition and underwent spinal decompression and/or fusion surgery. Participants completed the RAND-36 (to generate the physical component score [PCS] and mental component score [MCS]), Oswestry Disability Index (ODI), the numeric rating scale (NRS) for pain, Patient-Reported Outcomes Measurement Information System (PROMIS) pain interference, and a GAC item. Randomeffects models were used to investigate the sensitivity of PROs to the GAC and their responsiveness over time (i.e., PRO main effects and PRO-by-time interactions, respectively).

RESULTS The study sample included 168 patients (mean age 61 years, 50\% female) with preoperative and up to 12 months of postoperative data. Random-effects models revealed significant main effects for all PROs. Significant timeby-PRO interactions were detected for the PCS, PROMIS, ODI, and NRS ( $p<0.0005$ in all cases), but not for the MCS. Further examination revealed different sensitivity of the PROs to the GAC at different times. The NRS, PROMIS, and PCS showed higher sensitivity early after surgery, and the PCS evinced a marked drop in sensitivity to the GAC at about 8 months postsurgery.

CONCLUSIONS All PROs currently included in the spine outcome core measures are associated with patients' subjective assessment of a clinically important change, and all but the MCS scores are responsive to such change. Based on these findings, the core spine PROs could be reduced to include fewer estimates of pain. The authors suggest replacing the less responsive measures with tools that help to characterize factors that are driving the patients' subjective assessment of change and that meaningfully address some of the higher levels in the hierarchy of quality-of-life outcomes.

https://thejns.org/doi/abs/10.3171/2019.12.SPINE191367

KEYWORDS spine; quality of life; patient-reported outcomes; responsiveness; redundancy

$\mathrm{S}$ PINE outcome research has progressed in important ways over the past 2 decades. On Deyo and colleagues' recommendations of using a standard spine outcome battery of patient-reported outcomes (PROs), ${ }^{7}$ study results across clinics and investigators became more directly comparable. This standardization has enabled a more evidence-driven research base on which to make de- cisions about treatment choices. ${ }^{1,17}$ Nonetheless, the passage of time has led to a larger selection of measures and methods for detecting outcomes and change over time in clinical research studies. Given the challenges of maintaining high-quality data in clinical studies, it would be important to evaluate the contribution of each PRO to confirm that it merits the corresponding respondent burden

ABBREVIATIONS GAC = global assessment of change; HIPAA = Health Information Portability and Accountability Act; $M C S=$ mental component score; NRS = numeric rating scale; $\mathrm{ODI}=$ Oswestry Disability Index; $\mathrm{PCS}=$ physical component score; $\mathrm{PRO}=$ patient-reported outcome; PROMIS = Patient-Reported Outcomes Measurement Information System.

SUBMITTED November 13, 2019. ACCEPTED December 31, 2019.

INCLUDE WHEN CITING Published online February 21, 2020; DOI: 10.3171/2019.12.SPINE191367. 
and to consider whether relevant domains are missed or not measured as well as they could be.

Interest in interpreting change over time in PROs has led to a helpful body of research defining responsiveness ${ }^{36}$ and examining methodological differences in characterizing the change over time ${ }^{22,34}$ and theoretical work highlighting its nuances. ${ }^{33,35}$ Generally speaking, one characterizes the responsiveness of a tool using external indicators of change (i.e., anchors) and/or distribution-based methods (e.g., one-half standard deviation ${ }^{6,23}$ ). The most widely used anchor-based method is the patient's global assessment of change (GAC), ${ }^{37}$ whereby the patient answers whether their health or functional status is better, the same, or worse compared with the 3 months prior. This query thus operationalizes the patient's perspective on whether a noticeable or meaningful change has occurred. ${ }^{37}$ Distribution-based methods might utilize one of many available responsiveness formulas that are ratios of signal to noise (i.e., numerator is mean change, denominator is variation). ${ }^{9}$ These formulas can then be summarized in terms of effect size, ${ }^{31}$ and it is generally accepted that a medium effect size is clinically meaningful. ${ }^{21}$

With a growing empirical base, researchers have documented that responsiveness is not a static attribute of a measure but rather is a contextualized attribute that varies as a function of who is being analyzed, which scores are being contrasted, and what type of changes are being quantified. ${ }^{4}$ This contextual quality makes it difficult to hone in on a single value for a minimum clinically important difference (MCID). For this reason, the published MCIDs for spine outcome measures are variable..$^{23,24,30}$ Indeed, MCID has been reported as moderate to large in early stages of recovery from spine surgery; over time smaller and smaller changes become important. ${ }^{29}$

Given the importance of evaluating the benefit of spine surgery using measures that are not only standardized but also nonredundant and responsive, we aimed to examine the spine PROs' association with clinically important change, and relative responsiveness in explaining variance in patients' GAC.

\section{Methods}

\section{Sample and Design}

This longitudinal study included adults who were recruited from 4 active spine surgery practices from an academic teaching hospital. Patients older than 18 years who were scheduled to undergo elective surgery for degenerative lumbar spinal disorder of disc herniation, neurogenic claudication, degenerative spondylolisthesis, or lytic spondylolisthesis were included. Patients were excluded if they had prior lumbar surgery at the same level or were unable to understand and complete the survey-related documents in the English language. Eligible patients were recruited consecutively, and study participation was thoroughly explained. All patients provided written informed consent prior to completing any questionnaires. Data were collected online or by mail preoperatively (up to 2 baselines) and at approximately 6 weeks, 3 months, 6 months, and 12 months postsurgery using a secure, Health Information Portability and Accountability Act (HIPAA)-compliant interface (surveygizmo.com). The study was reviewed and approved by the Sunnybrook Health Sciences Centre's institutional review board.

\section{Outcome Measures}

\section{Self-Report Measures}

The Medical Outcomes Study Short-Form (RAND36) ${ }^{10}$ was used to assess physical and emotional functioning via the physical component score (PCS) and mental component score (MCS). Spine-specific disability was measured using the 10-item Oswestry Disability Index (ODI). ${ }^{8}$ Pain impact was measured using 4 numeric rating scale (NRS) items to assess pain at rest, pain with activity, back pain, and leg pain, ${ }^{5}$ and the 6 -item Patient-Reported Outcomes Measurement Information System (PROMIS) pain interference short form ${ }^{2}$ was scored using standardized scoring tables provided in the PROMIS manual. To facilitate interpretation of the PRO measures, all were rescored such that high scores reflect better functioning; i.e., ODI, NRS, and PROMIS pain interference scores were reverse-scored to achieve this orientation. The NRS summary score was computed by taking the sum of the 4 items and subtracting it from 40 (the maximum total). The PROMIS pain interference score was then subtracted from 100. Clinically important change was assessed using an anchor-based technique, the GAC item, "Compared to three months ago, how would you rate your health in general now?" Response options were recoded to make intuitive sense, with a range from -2 (much worse) to +2 (much better) and a score of 0 indicating same/no change. An option to decline to answer was coded as missing. This item was included in all but the first baseline data collection timepoints. Demographic characteristics were included for descriptive purposes and to serve as control variables.

\section{Statistical Analysis}

Random-effects models ${ }^{12}$ were used to investigate the relationship of each PRO in predicting GAC over time. This relationship can be separated into its sensitivity (as reflected by PRO main effects) and its responsiveness to clinically important change (i.e., differential change in GAC over time as reflected by its PRO-by-time interaction). Analyses were conducted on the subsample of patients with at least 2 follow-up records $(n=168)$. The PRO independent variables were standardized for use in multivariable analysis (mean 50, SD 10) to facilitate comparison of parameter estimates. The patient identifier was treated as a random effect, while PRO, time, and PRO-by-time interaction were treated as fixed effects. For the purpose of the random-effects models, time was expressed in days, and for plotting results, in months. Thus, time remained a continuous variable to reflect the varying windows separating different timepoints. We began by testing simple main effects of PRO scores and time in predicting GAC scores over time, and then added the PRO-by-time interactions. Final models were selected on the basis of a type I error rate of 0.05 . Stata (version 15 , StataCorp), R (release 3.4), and/or IBM SPSS (version 26, IBM Corp.) were used for all analyses. 


\section{Results \\ Sample}

The surgical indication was leg pain with or without back pain. Table 1 shows the distribution of diagnoses and primary procedures and the demographic characteristics of the sample. The patients had a mean age of 61 years (SD 16 years) and an equal number of males and females. The sample had an average of almost 2 comorbidities among the 14 presented (range $0-7$ ), with the most common being high blood pressure and osteoarthritis. BMI averaged a high 28.5. The majority of the sample had more than a college degree, and about one-third was retired. Less than $5 \%$ reported being on workers' compensation currently or in the recent past.

Table 2 shows descriptive statistics for the GAC and PRO scores at baseline, reflecting a sample that endorsed being slightly worse off prior to surgery and with poor scores on measures of physical and mental functioning and pain. Figure 1 shows the mean GAC over follow-up. As expected, patients reported substantial improvement soon after surgery up to about 6 months postsurgery. After that, patients reported incremental improvements that were smaller in magnitude.

\section{Relationship of PROs to GAC Scores}

Table 3 shows results of the random-effects models testing the main effects of time and each of the 5 PRO scores. All PROs were associated over time with the GAC scores, but time was not consistently related to the GAC score in any linear fashion. Only in the main-effects model including the NRS pain score was time associated with the subjective endorsement of improvement $(p<0.03)$.

\section{Responsiveness of PROs}

Random-effects models revealed significant time-byPRO interactions in predicting GAC scores over time for the PCS, PROMIS pain interference, ODI, and NRS ( $\mathrm{p}<$ 0.0005 in all cases), but not for the MCS (Table 3). Figure 2 displays the standardized regression coefficients (betas) for the main effects and interaction terms using time in months. This illustrates that the PRO most associated with GAC as a main effect was the NRS, but the largest responsiveness (interaction) effect was with the PROMIS pain interference.

Thus, in the longitudinal models, PROs all had significant associations with GAC. For main effects, the NRS score was the most sensitive, while the PCS was the least (Fig. 2 bars). There were also significant time-by-PRO interactions. Of note, PROs showed different sensitivity to GAC at different time periods (Fig. 2 line). To elucidate the substantive meaning of these interactions, we created a series of figures. Supplemental Fig. 1 shows scatterplots of GAC by PRO at each timepoint, including best-linearfit lines. Figure 3 draws on Supplemental Fig. 1, showing how the slope coefficients (main effects) reflected there varied over time (interactions). These figures suggest different sensitivity of the PROs to GAC at different times. The NRS, PROMIS, and PCS all evinced a "bump" early after surgery, suggesting higher sensitivity at that time window. In contrast, ODI and MCS had less of a "bump."
TABLE 1. Descriptive statistics of study sample

\begin{tabular}{|c|c|}
\hline Variable & Value \\
\hline \multicolumn{2}{|l|}{ Age, yrs } \\
\hline Mean (SD) & $60.59(16.12)$ \\
\hline Range & $18-91$ \\
\hline \multicolumn{2}{|l|}{ Comorbidities (of 14 presented)* } \\
\hline Mean (SD) & $1.96(1.77)$ \\
\hline Range & $0-7$ \\
\hline \multicolumn{2}{|l|}{ BMI $(n=159)$} \\
\hline Mean (SD) & $28.54(5.34)$ \\
\hline Range & $17-40$ \\
\hline \multicolumn{2}{|l|}{ Follow-up time, days } \\
\hline Mean (SD) & $255(117)$ \\
\hline Range & $41-595$ \\
\hline \multicolumn{2}{|l|}{ Sex } \\
\hline Male & $84(50)$ \\
\hline Female & $84(50)$ \\
\hline Missing & 0 \\
\hline \multicolumn{2}{|l|}{ Primary diagnosis(es)† } \\
\hline Disc herniation & $60(36)$ \\
\hline Radiculopathy/sciatica & $25(15)$ \\
\hline Spinal stenosis w/ neurogenic claudication & $108(64)$ \\
\hline Spondylolisthesis (lytic or NOS) & $8(5)$ \\
\hline Spondylolisthesis (degenerative) & $36(21)$ \\
\hline Scoliosis_deformity & $8(5)$ \\
\hline \multicolumn{2}{|l|}{ Primary procedure(s) $\dagger$} \\
\hline Laminectomy & $91(54)$ \\
\hline Discectomy & $102(61)$ \\
\hline Fusion & $52(31)$ \\
\hline Laminectomy \& discectomy & $59(35)$ \\
\hline Laminectomy \& fusion & $24(14)$ \\
\hline Discectomy \& fusion & $10(6)$ \\
\hline \multicolumn{2}{|l|}{ Specific comorbidities (back pain excluded)* } \\
\hline Anemia or other blood disease & $4(2)$ \\
\hline Cancer & $8(5)$ \\
\hline Depression & $14(8)$ \\
\hline Diabetes & $12(7)$ \\
\hline Heart disease & $15(9)$ \\
\hline High blood pressure & $46(27)$ \\
\hline Kidney disease & $1(1)$ \\
\hline Liver disease & $1(1)$ \\
\hline Lung disease & $7(4)$ \\
\hline Osteoarthritis, degenerative arthritis & $45(27)$ \\
\hline Other & $49(29)$ \\
\hline Rheumatoid arthritis & $12(7)$ \\
\hline Ulcer or stomach disease & $3(2)$ \\
\hline \multicolumn{2}{|l|}{ Marital status } \\
\hline Married & $111(70)$ \\
\hline Widowed & $8(5)$ \\
\hline Living w/ significant other & $10(6)$ \\
\hline Single (never married) & $17(11)$ \\
\hline
\end{tabular}


» CONTINUED FROM PAGE 108

TABLE 1. Descriptive statistics of study sample

\begin{tabular}{|c|c|}
\hline Variable & Value \\
\hline \multicolumn{2}{|l|}{ Marital status (continued) } \\
\hline Divorced/separated & $11(7)$ \\
\hline Civil union/domestic partner & $1(1)$ \\
\hline Missing & 10 \\
\hline \multicolumn{2}{|l|}{ Race } \\
\hline American Indian or Alaskan Native & $1(1)$ \\
\hline Asian & $6(4)$ \\
\hline Black or African American & $1(1)$ \\
\hline Native Hawaiian or other Pacific Islander & $0(0)$ \\
\hline White & $153(95)$ \\
\hline Missing & 7 \\
\hline \multicolumn{2}{|l|}{ Education } \\
\hline Less than high school & $8(6)$ \\
\hline Graduated from high school or GED & $23(16)$ \\
\hline Some college or technical school & $31(22)$ \\
\hline Graduated from college & $42(30)$ \\
\hline Postgraduate school or degree & $3(27)$ \\
\hline Missing & 26 \\
\hline \multicolumn{2}{|l|}{ Employment status* } \\
\hline Working & $48(29)$ \\
\hline On leave of absence & $8(5)$ \\
\hline Retired (not due to ill health) & $52(31)$ \\
\hline Disabled \&/or retired because of ill health & $7(4)$ \\
\hline Homemaker & $5(3)$ \\
\hline Unemployed & $4(2)$ \\
\hline Student & $2(1)$ \\
\hline Other & $10(6)$ \\
\hline Not working & $32(19)$ \\
\hline \multicolumn{2}{|l|}{ Smoking status } \\
\hline Never smoked/used tobacco & $80(50)$ \\
\hline Used to smoke/use tobacco & $68(43)$ \\
\hline Current smoker/use tobacco & $12(8)$ \\
\hline Missing & 8 \\
\hline \multicolumn{2}{|l|}{ Legal action* } \\
\hline Not considering any legal action & $165(98)$ \\
\hline My legal action is pending & $2(1)$ \\
\hline My legal action has been resolved in my favor & $1(1)$ \\
\hline \multicolumn{2}{|l|}{ Workers' compensation status* } \\
\hline I am not planning to apply for workers' compensation & $161(96)$ \\
\hline I used to receive it, but do not now & $0(0)$ \\
\hline I am planning to apply for it & $1(1)$ \\
\hline I have applied for it & $1(1)$ \\
\hline I am currently receiving workers' compensation & $5(3)$ \\
\hline
\end{tabular}

GED = General Educational Development; NOS = not otherwise specified.

Percentages are based on the number of patients with existing data.

${ }^{*}$ For these topics, a nonresponse was counted as the absence of the event in question (e.g., no disease, not working, no legal action).

† Values may sum to greater than $100 \%$ because more than one may apply.
TABLE 2. Descriptive statistics of PROs at baseline

\begin{tabular}{llrrrr}
\hline \multicolumn{1}{c}{ Item or (Sub)scale } & Mean & SD & Min & Max \\
\hline GAC (recoded) $(n=164)$ & -0.50 & 1.07 & -2 & 2 \\
\hline \multirow{5}{*}{ PROs } & RAND-36 PCS $(n=162)$ & 29.88 & 6.81 & 14 & 46 \\
\cline { 2 - 6 } & RAND-36 MCS $(n=162)$ & 40.42 & 10.58 & 15 & 61 \\
\cline { 2 - 6 } & PROMIS pain interference & 34.92 & 7.40 & 22 & 59 \\
& $(n=161)^{*}$ & & & & \\
\cline { 2 - 6 } & ODI $(n=164)^{*}$ & 56.15 & 16.01 & 12 & 100 \\
\cline { 2 - 6 } & NRS $(n=164)^{*}$ & 16.32 & 8.71 & 0 & 38 \\
\hline
\end{tabular}

PRO raw scores are shown here, whereas statistical models utilized standardized scores (mean 50, SD 10) to facilitate comparisons.

${ }^{*}$ Rescaled so that higher scores reflect better functioning.

Of note, the PCS evinced a marked drop in sensitivity to GAC at about 8 months postsurgery.

\section{Discussion}

All of the PROs currently included in the spine outcome core measures are associated with patients' subjective assessment of clinically important change, and all but the MCS are responsive at most time windows to clinically important change. Three measures show substantial similarity in their relationship with the GAC (i.e., the NRS, ODI, and PROMIS pain interference scores), all of which are focused on pain.

Based on these findings, the core spine PROs could be reduced to include fewer estimates of pain. Deciding on which PRO to drop would depend on one's emphasis. For example, the NRS (for back or leg pain only) or the more multidimensional ODI would be the PRO of choice if one emphasizes consistent sensitivity to the GAC subjective indicator of change. The only time window during which the PROMIS pain interference's sensitivity is comparable to the NRS' or ODI's is soon after surgery.

The two composite scores from the generic RAND-36 show the least sensitivity to the GAC. While this generic measure is helpful in characterizing patient samples according to large population- and diagnostic-subgroup norms, it does not seem particularly informative about postsurgical recovery.

This finding may suggest that spine outcome researchers consider including a briefer generic health measure, such as the PROMIS-10, and allocating space in their PRO data collection to capturing other valuable information. For example, in our clinic we have found that including measures of cognitive appraisal processes that underlie patient responses to PRO measures has been helpful for understanding group differences in self-assessed change ${ }^{29}$ and for detecting response-shift effects..$^{13,28}$ Measuring appraisal processes can help to clarify the patient's emphases and values and create a better understanding between surgeon and patient. We have found, for example, that early after surgery, about one-quarter of patients disagree with their surgeon's assessment of change postsurgery and that these patients tended to have worsened mental health and leg pain. ${ }^{26}$ Having more information about patients' underlying cognitive appraisal processes-frame of refer- 


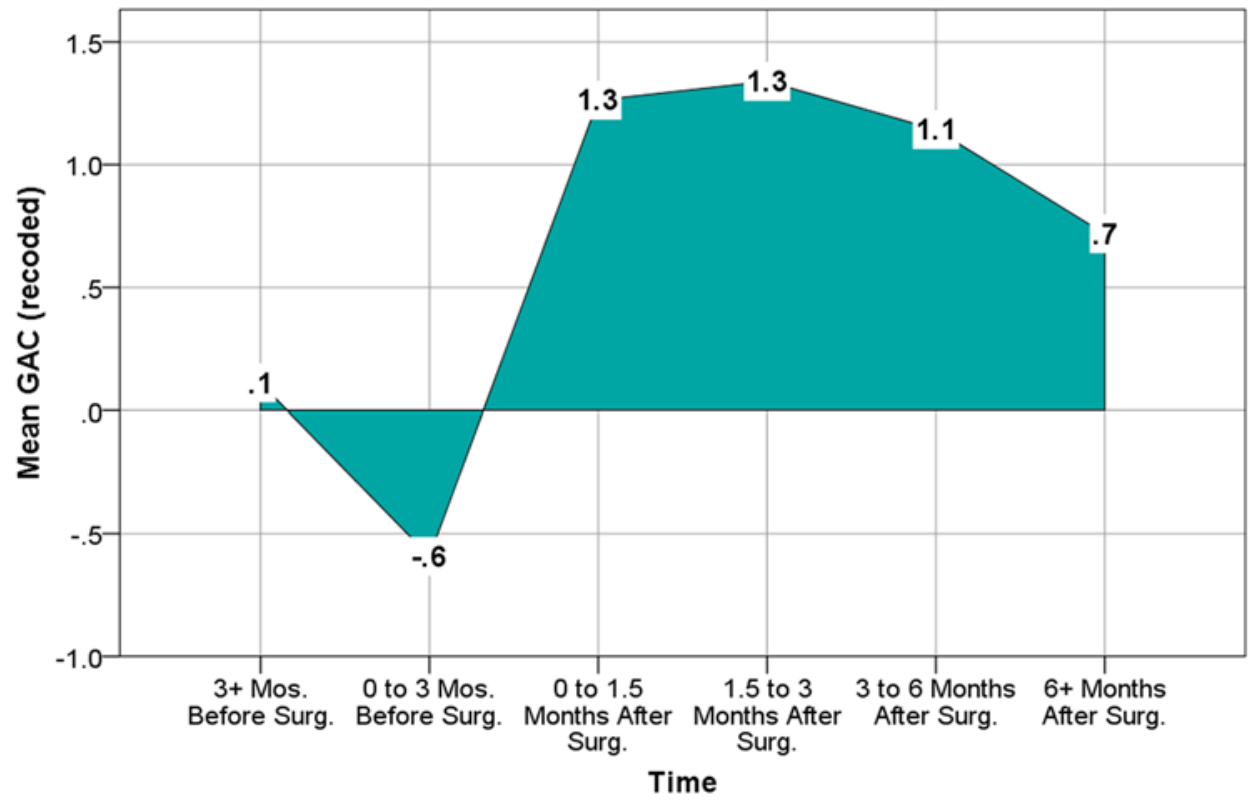

FIG. 1. Mean GAC over follow-up. As expected, patients reported substantial improvement soon after surgery up to about 6 months postsurgery. After that, patients reported improvements that were smaller in magnitude. Figure is available in color online only.

TABLE 3. Longitudinal random-effects models predicting the GAC score based on PROs

\begin{tabular}{|c|c|c|c|c|c|c|}
\hline & \multicolumn{3}{|c|}{ Main-Effects Model } & \multicolumn{3}{|c|}{ Interaction Model } \\
\hline & $\beta$ & SE & p Value & $\beta$ & SE & $p$ Value \\
\hline \multicolumn{7}{|l|}{ RAND-36 PCS } \\
\hline Time (days) & 0.00037 & 0.00040 & 0.359 & 0.01234 & 0.00229 & $<0.0005$ \\
\hline PRO & 0.04125 & 0.00560 & $<0.0005$ & 0.06105 & 0.00654 & $<0.0005$ \\
\hline Time-PRO interaction & & & & -0.00023 & 0.00004 & $<0.0005$ \\
\hline \multicolumn{7}{|l|}{ RAND-36 MCS } \\
\hline Time (days) & 0.00066 & 0.00036 & 0.073 & 0.00408 & 0.00209 & 0.053 \\
\hline PRO & 0.04340 & 0.00570 & $<0.0005$ & 0.04966 & 0.00681 & $<0.0005$ \\
\hline Time-PRO interaction & & & & -0.00007 & 0.00004 & 0.099 \\
\hline \multicolumn{7}{|l|}{ PROMIS pain interference* } \\
\hline Time (days) & -0.00032 & 0.00040 & 0.425 & 0.01577 & 0.00208 & $<0.0005$ \\
\hline PRO & 0.06494 & 0.00527 & $<0.0005$ & 0.09393 & 0.00612 & $<0.0005$ \\
\hline Time-PRO interaction & & & & -0.00030 & 0.00004 & $<0.0005$ \\
\hline \multicolumn{7}{|l|}{ ODI* } \\
\hline Time (days) & -0.00053 & 0.00037 & 0.150 & 0.01367 & 0.00209 & $<0.0005$ \\
\hline PRO & 0.08170 & 0.00546 & $<0.0005$ & 0.10383 & 0.00601 & $<0.0005$ \\
\hline Time-PRO interaction & & & & -0.00027 & 0.00004 & $<0.0005$ \\
\hline \multicolumn{7}{|l|}{$\mathrm{NRS}^{*}$} \\
\hline Time (days) & -0.00074 & 0.00034 & 0.030 & 0.01046 & 0.00186 & $<0.0005$ \\
\hline PRO & 0.09738 & 0.00457 & $<0.0005$ & 0.10976 & 0.00481 & $<0.0005$ \\
\hline Time-PRO interaction & & & & -0.00021 & 0.00003 & $<0.0005$ \\
\hline
\end{tabular}

Each PRO is standardized to have a mean 50 (SD 10). Boldface type indicates statistical significance.

* Score recoded such that high scores reflect better functioning. 


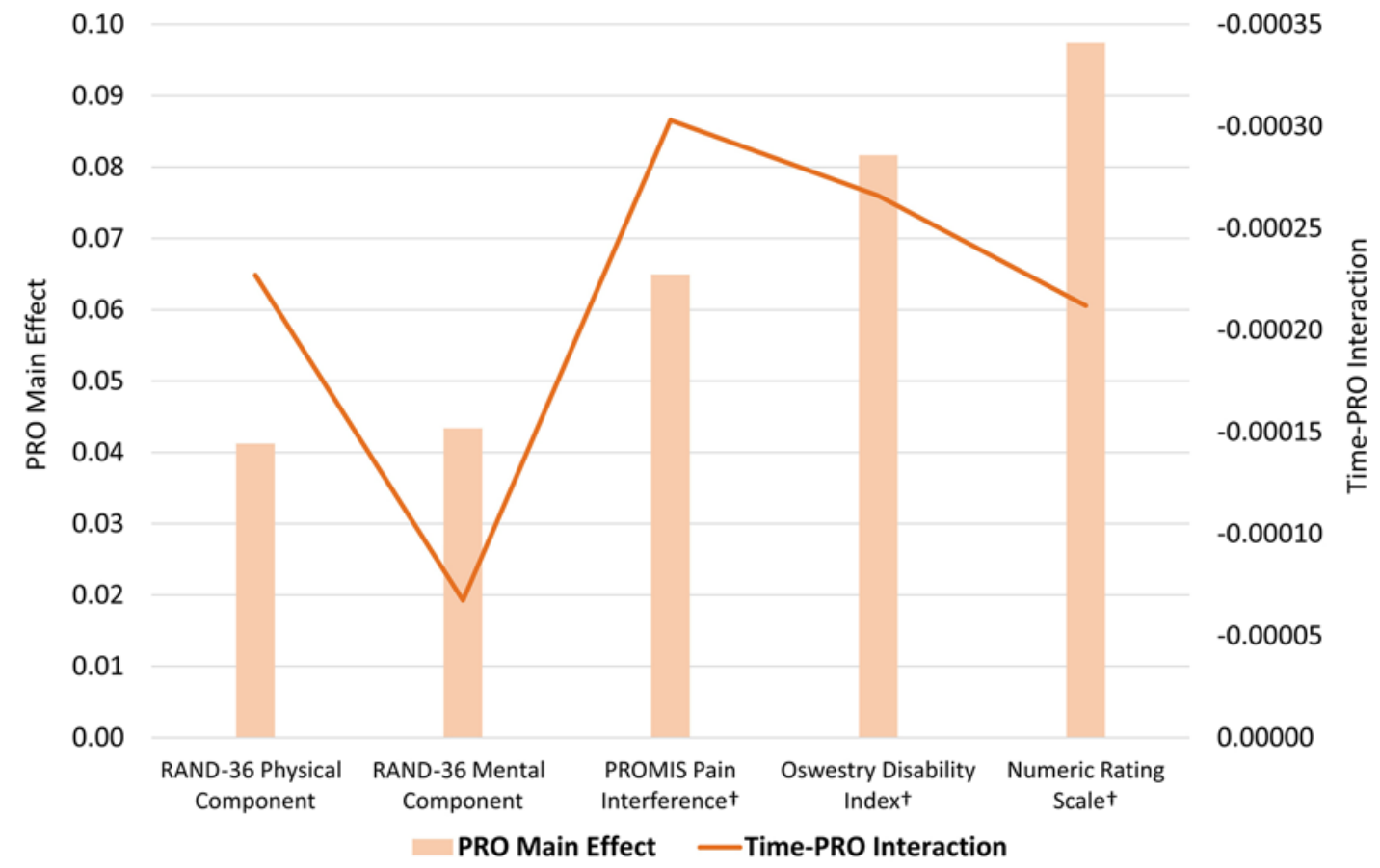

FIG. 2. PROs' relationships with GAC. The standardized regression coefficients (betas) are shown for the main effects and interaction terms using time in months. This illustrates that the PRO most associated with GAC as a main effect was the NRS, but the largest responsiveness (interaction) effect was with the PROMIS pain interference. Figure is available in color online only.

ence, standards of comparison, sampling of experience, and patterns of emphasis-can help to improve doctorpatient communication ${ }^{18,19}$ and the interpretation of PROs over time. ${ }^{27}$

Our findings may also suggest that the current mea- sures in the standard spine outcome battery may miss assessment of key constructs. For example, since the MCS did not evince strong responsiveness over time, it might be worthwhile to consider testing other measures of wellbeing or wellness in the battery. In her seminal paper con-

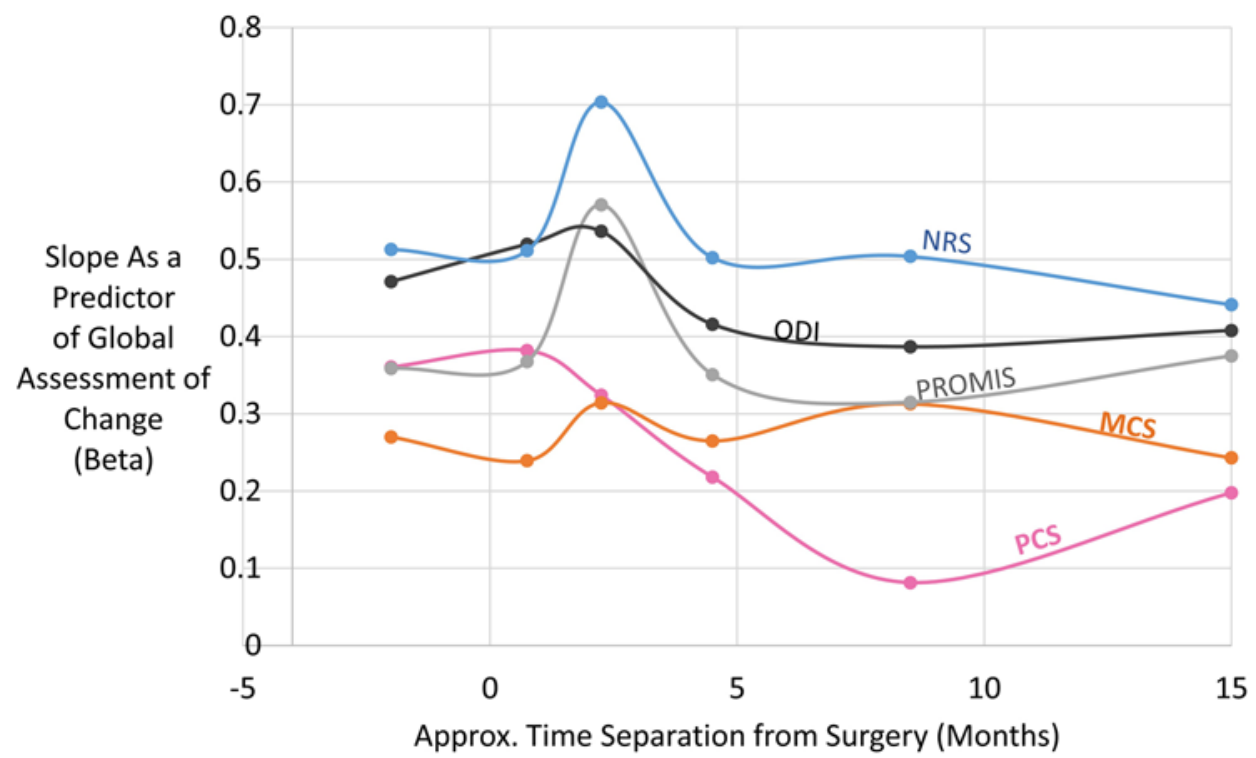

FIG. 3. Slope coefficients (main effects) over time. There was different sensitivity of the PROs to GAC at different times. The NRS, PROMIS, and PCS all evinced a "bump" early after surgery, suggesting higher sensitivity at that time window. In contrast, ODI and MCS had less of a "bump." Of note, PCS evinced a marked drop in sensitivity to GAC at about 8 months postsurgery. Figure is available in color online only. 
ceptualizing quality of life, Smith ${ }^{32}$ compared this multidimensional construct to Maslow's hierarchy of needs, ${ }^{14-16}$ with lower layers (e.g., physical functioning) serving as a necessary foundation for higher-level concepts, such as role performance, adaptability, and eudaemonic wellbeing. While physical functioning and pain are clearly important foundational outcomes for spine surgery, an improved sense of ability to perform desired roles (i.e., role performance), confidence in one's ability to deal with the challenges of life postsurgery (e.g., environmental mastery), and an enhanced sense of purpose in life and social connection (i.e., eudaemonic well-being) are also indicative of a fuller recovery.

While this study has clear advantages in its longitudinal data of spine clinic patients, its limitations should be acknowledged. The study has the advantage of including patients with a broad range of spinal pathologies/procedures; its findings do not, however, differentiate by pathology or procedure. Another limitation is that, largely because of sample size, we did not fully explore study findings that reflect nonlinear relationships over time (e.g., the inverted-U-shaped pattern shown in Fig. 3). Also, the PRO redundancy detected in our findings may suggest that patients found the survey burdensome and reacted by answering mechanically or in other undesirable ways that biased results. For example, straightlining is a common survey response whereby the individual selects the same response option regardless of the question. ${ }^{25}$ Such response biases can affect validity and power. ${ }^{25}$ Research by members of our group has indicated, however, that patients do not experience even long surveys as burdensome if they are varied and comprehensive. ${ }^{3}$ Finally, there is growing recognition that responsiveness is mediated by attitudinal, behavioral, and framing effects. ${ }^{33}$ Attitudinal mediators would include, for example, social desirability (e.g., what do patients think their provider wants to hear?). Behavioral mediators would include, for example, implicit theories of change,$^{20}$ effort justification, or cognitive dissonance..$^{33}$ Framing effects might involve the way the time frame is grouped (i.e., past day, week, or month) and/or what symptoms are considered when answering a GAC. ${ }^{32}$ In terms of evaluating the success of lumbar spine surgery using the GAC, it may be beneficial to reference the health condition for which the surgery was recommended when formulating the question in order to reduce response ambiguity and ensure clinical relevance. ${ }^{11}$ These dynamics were not addressed in the current study. Future research might evaluate the impact of these mediators on spine surgery outcomes.

\section{Conclusions}

The present work supports the responsiveness of most of the spine PROs but suggests that several provide little additional information about recovery. Although all PROs were associated with GAC, they differed in their responsiveness over time. We suggest replacing the less responsive measures with tools that help to characterize factors that are driving the patients' subjective assessments of change, and that meaningfully address some of the higher levels in the hierarchy of quality-of-life outcomes.

\section{Acknowledgments}

We are grateful to Monica Kunz and Katrine Milner for assistance in implementing the data collection for this project.

This work was funded by the Feldberg Chair in Spinal Research, Sunnybrook Health Sciences Centre.

\section{References}

1. Allen RT, Rihn JA, Glassman SD, Currier B, Albert TJ, Phillips FM: An evidence-based approach to spine surgery. Am J Med Qual 24 (6 Suppl):15S-24S, 2009

2. Askew RL, Cook KF, Revicki DA, Cella D, Amtmann D: Evidence from diverse clinical populations supported clinical validity of PROMIS pain interference and pain behavior. J Clin Epidemiol 73:103-111, 2016

3. Atkinson TM, Schwartz CE, Goldstein L, Garcia I, Storfer DF, Li Y, et al: Perceptions of response burden associated with completion of patient-reported outcome assessments in oncology. Value Health 22:225-230, 2019

4. Beaton DE, Bombardier C, Katz JN, Wright JG: A taxonomy for responsiveness. J Clin Epidemiol 54:1204-1217, 2001

5. Childs JD, Piva SR, Fritz JM: Responsiveness of the numeric pain rating scale in patients with low back pain. Spine (Phila Pa 1976) 30:1331-1334, 2005

6. Copay AG, Subach BR, Glassman SD, Polly DW Jr, Schuler TC: Understanding the minimum clinically important difference: a review of concepts and methods. Spine J 7:541-546, 2007

7. Deyo RA, Battie M, Beurskens AJ, Bombardier C, Croft P, Koes B, et al: Outcome measures for low back pain research. A proposal for standardized use. Spine (Phila Pa 1976) 23:2003-2013, 1998

8. Fairbank JC, Pynsent PB: The Oswestry Disability Index. Spine (Phila Pa 1976) 25:2940-2952, 2000

9. Guyatt GH, Osoba D, Wu AW, Wyrwich KW, Norman GR: Methods to explain the clinical significance of health status measures. Mayo Clin Proc 77:371-383, 2002

10. Hays RD, Sherbourne CD, Mazel RM: The RAND 36-item health survey 1.0. Health Econ 2:217-227, 1993

11. Kamper SJ, Maher CG, Mackay G: Global rating of change scales: a review of strengths and weaknesses and considerations for design. J Manual Manip Ther 17:163170, 2009

12. Laird NM, Ware JH: Random-effects models for longitudinal data. Biometrics 38:963-974, 1982

13. Li Y, Rapkin BD: Classification and regression tree analysis to identify complex cognitive paths underlying quality of life response shifts: a study of individuals living with HIV/AIDS. J Clin Epidemiol 62:1138-1147, 2009

14. Maslow A: Motivation and Personality. New York: Harper \& Row, 1954

15. Maslow A, Lowery R (eds): Toward a Psychology of Being, ed 3. New York: Wiley \& Sons, 1998

16. Maslow AH: A theory of human motivation. Psychol Rev 50:370-396, 1943

17. Mirza SK, Deyo RA, Heagerty PJ, Turner JA, Martin BI, Comstock BA: One-year outcomes of surgical versus nonsurgical treatments for discogenic back pain: a communitybased prospective cohort study. Spine J 13:1421-1433, 2013

18. Nevadunsky NS, Brodt Z, Eti S, Selwyn P, Rapkin B, Einstein $\mathrm{M}$, et al: Utilization of palliative medicine in a racially and ethnically diverse population of women with gynecologic malignancies. Cancer Res 71:5026, 2011

19. Nevadunsky NS, Gordon S, Spoozak L, Van Arsdale A, Hou Y, Klobocista M, et al: The role and timing of palliative medicine consultation for women with gynecologic malignancies: association with end of life interventions and direct hospital costs. Gynecol Oncol 132:3-7, 2014

20. Norman G: Hi! How are you? Response shift, implicit theo- 
ries and differing epistemologies. Qual Life Res 12:239 249, 2003

21. Norman GR, Sloan JA, Wyrwich KW: Interpretation of changes in health-related quality of life: the remarkable universality of half a standard deviation. Med Care 41:582-592, 2003

22. Norman GR, Wyrwich KW, Patrick DL: The mathematical relationship among different forms of responsiveness coefficients. Qual Life Res 16:815-822, 2007

23. Ostelo RW, Deyo RA, Stratford P, Waddell G, Croft P, Von Korff M, et al: Interpreting change scores for pain and functional status in low back pain: towards international consensus regarding minimal important change. Spine (Phila Pa 1976) 33:90-94, 2008

24. Parker SL, Adogwa O, Mendenhall SK, Shau DN, Anderson WN, Cheng JS, et al: Determination of minimum clinically important difference (MCID) in pain, disability, and quality of life after revision fusion for symptomatic pseudoarthrosis. Spine J 12:1122-1128, 2012

25. Podsakoff PM, MacKenzie SB, Lee JY, Podsakoff NP: Common method biases in behavioral research: a critical review of the literature and recommended remedies. J Appl Psychol 88:879-903, 2003

26. Schwartz CE, Ayandeh A, Finkelstein JA: When patients and surgeons disagree about surgical outcome: investigating patient factors and chart note communication. Health Qual Life Outcomes 13:161, 2015

27. Schwartz CE, Finkelstein JA, Rapkin BD: Appraisal assessment in patient-reported outcome research: methods for uncovering the personal context and meaning of quality of life. Qual Life Res 26:545-554, 2017

28. Schwartz CE, Powell VE, Rapkin BD: When global rating of change contradicts observed change: examining appraisal processes underlying paradoxical responses over time. Qual Life Res 26:847-857, 2017

29. Schwartz CE, Zhang J, Rapkin BD, Finkelstein JA: Reconsidering the minimally important difference: evidence of instability over time and across groups. Spine J 19:726-734, 2019

30. Schwind J, Learman K, O'Halloran B, Showalter C, Cook C: Different minimally important clinical difference (MCID) scores lead to different clinical prediction rules for the Oswestry disability index for the same sample of patients. $\mathbf{J}$ Manual Manip Ther 21:71-78, 2013

31. Sloan J, Symonds T, Vargas-Chanes D, Fridley B: Practical guidelines for assessing the clinical significance of healthrelated quality of life changes within clinical trials. Drug Inf J 37:23-31, 2003

32. Smith JA: The idea of health: a philosophical inquiry. ANS Adv Nurs Sci 3:43-50, 1981

33. Swartz RJ, Schwartz C, Basch E, Cai L, Fairclough DL, McLeod L, et al: The king's foot of patient-reported outcomes: current practices and new developments for the measurement of change. Qual Life Res 20:1159-1167, 2011
34. Terwee CB, Dekker FW, Wiersinga WM, Prummel MF, Bossuyt PM: On assessing responsiveness of health-related quality of life instruments: guidelines for instrument evaluation. Qual Life Res 12:349-362, 2003

35. Wright A, Hannon J, Hegedus EJ, Kavchak AE: Clinimetrics corner: a closer look at the minimal clinically important difference (MCID). J Manual Manip Ther 20:160-166, 2012

36. Wyrwich KW, Bullinger M, Aaronson N, Hays RD, Patrick DL, Symonds T: Estimating clinically significant differences in quality of life outcomes. Qual Life Res 14:285-295, 2005

37. Wyrwich KW, Tardino VMS: Understanding global transition assessments. Qual Life Res 15:995-1004, 2006

\section{Disclosures}

Dr. Finkelstein: consultant for Stryker Canada and institutional education support from Stryker Canada and Zimmer Biomet.

\section{Author Contributions}

Conception and design: Schwartz, Finkelstein. Acquisition of data: Balasuberamaniam, Shrikumar, Wasim, Finkelstein. Analysis and interpretation of data: Schwartz, Stark, Finkelstein. Drafting the article: Schwartz, Stark. Critically revising the article: all authors. Reviewed submitted version of manuscript: all authors. Approved the final version of the manuscript on behalf of all authors: Schwartz. Statistical analysis: Schwartz, Stark. Administrative/technical/material support: Balasuberamaniam, Shrikumar, Wasim, Finkelstein. Study supervision: Schwartz, Finkelstein.

\section{Supplemental Information \\ Online-Only Content}

Supplemental material is available with the online version of the article.

Supplemental Fig. 1. https://thejns.org/doi/suppl/10.3171/2019. 12.SPINE191367.

\section{Previous Presentations}

This work was presented as an oral brief presentation at the International Society for Quality of Life Research 26th Annual Conference, San Diego, California, October 20-23, 2019.

\section{Correspondence}

Carolyn E. Schwartz: DeltaQuest Foundation, Inc., Concord, MA. carolyn.schwartz@deltaquest.org. 